\title{
NÉMESIS DE PHILIP ROTH FRENTE AL COVID-19 ACTUAL. LA LITERATURA, LAS ENFERMEDADES DEL PASADO Y LA PANDEMIA QUE ESTAMOS PADECIENDO
}

\section{Philip Roth's Nemesis in the Current Covid-19. The Literature, the Diseases of the Past and the Pandemic That We Are Suffering.}

\author{
Covadonga PIPA MUÑIZa; Luis Vicente SÁNCHEZ FERNÁNDEZ

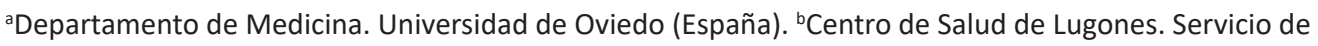 \\ Atención Continuada. SESPA (España).
}

Correo electrónico: sanchezvicente@uniovi.es

Fecha de recepción: 3 de septiembre de 2020

Fecha de aceptación: 16 de septiembre de 2020

Fecha de publicación: 29 de enero de 2021

\section{Resumen}

La lectura de Némesis, 2010, evoca un gran parlelismo con la pandemia de COVID-19 que nos asuela. Nuestro autor de referencia plantea una epidemia de poliomielitis, antes del remedio vacunal, en EEUU. La zona novelada es Newark, un barrio marginal de Weequahic, en 1944, en plena II Guerra Mundial. La úbicación escogida estaba ocupada mayoritariamente por judíos, el pueblo elegido por Dios, y la poliomielitis se encargó de poner al descubierto las miserias internas de esta población; la pandemia actual descubre las nuestras. La única solución posible planteada por Roth en aquella sociedad desestructurada era la aparición de la diosa vengadora Némesis para que impusiese una justicia retributiva en el mundo caótico de la novela. Es posible que si no aparece para nosotros y no actúa sobre los desequilibrios socio-económicos que trae aparejados este coronavirus la consecuencia será un golpe mortal para la opulenta e irresponsable sociedad occidental.

Palabras clave: Némesis; poliomielitis; epidemia; COVID-19.

\section{Abstract}

Reading Nemesis, 2010, it evokes me a great parallel to the COVID-19 pandemic that devastates us. Our reference author raises a situation of polio epidemic, before the vaccine remedy, in the 


\title{
NÉMESIS DE PHILIP ROTH FRENTE AL COVID-19 ACTUAL. LA LITERATURA, LAS \\ ENFERMEDADES DEL PASADO Y LA PANDEMIA QUE ESTAMOS PADECIENDO. COVADONGA PIPA MUÑIZ; LUIS VICENTE SÁNCHEZ FERNÁNDEZ
}

\begin{abstract}
USA. The fictionalized area corresponds to Newark, a marginal neighborhood in Weequahic, in 1944, in the midst of World War II. The chosen location was made up of mainly by Jews, the people chosen by God, and poliomyelitis exposed the internal miseries of this population; the current pandemic uncovers ours. The only possible solution proposed by Roth in that unstructured society was the appearance of the avenging goddess Nemesis to impose retributive justice in the chaotic world of the novel. It is possible that if it does not appear for us and does not act on the socioeconomic imbalances that this coronavirus brings with it, the consequence will be a mortal blow for the opulent and irresponsible Western society.
\end{abstract}

Keywords: Nemesis; poliomyelitis; epidemic; COVID-19.

\section{INTRODUCCIÓN}

La literatura, y por ende el cine o el teatro, está llena de médicos escritores y de escritores-pacientes que publicaron sus dolencias bajo la forma de novelas. En el primer caso tenemos a Arthur Conan Doyle (1859-1930) ${ }^{a}$, Antón Chéjov, (1860-1904), Pío Baroja (1872-1956), Gregorio Marañón (1887-1960) y un largo etcétera ${ }^{1}$. En el segundo nivel contamos con Susan Sontag (1933-2004) y Aleksandr Solzchenitsyn (19182008) personajes que padecieron cáncer y que escribieron relatos que dieron a la luz nuevos enfoques personales consiguiendo crear una nueva senda para los dolientes tal como reflejaron en La enfermedad y sus metáforas, 1978 y Pabellón de cáncer, 1966 respectivamente. En la misma línea también referimos a determinadas narraciones donde los médicos son los protagonistas principales, caso de Noah Gordon (1916) y El último judío, 1999, Sinuhé el egipcio, 1945, de Mika Waltari (1908-1979) o Thomas Mann (18751955) con La montaña mágica, 1924.

Con estos ejemplos queremos manifestar que la literatura universal es una fuente magnífica para analizar los sentimientos de los convalecientes, comprender mejor la relación médico-paciente y las dudas de los profesionales, apreciar el temor ante un diagnóstico infausto, el miedo a la muerte, etc. Razonamiento que aplicamos al análisis de Némesis, 2010, de Philip Roth (1933-2018) con la COVID-19 al fondo.

\section{NÉMESIS FRENTE AL COVID-19}

En Némesis Philip Roth ${ }^{2}$ saca a flote una serie de dificultades de interacción entre la vecindad, principalmente judía, que se aceleraron cuando apareció de forma brusca un brote de polomielitis; enfermedad que en aquel tiempo no contaba con remedio alguno. Uno de los primeros errores lo llevó a cabo el alcade de Newark cuando, sin ninguna base científica, emitió un edicto titulado "Acabemos con las moscas" en el que manifestaba que cuando estos insectos se posasen "con sus patas cargadas de gérmenes en uno de los niños les inoculara la polio".

Aprovechando esta idea otros culpaban a los gatos callejeros, los perros vagabundos y las palomas que volaban por las proximidades de las casas y que defecaban en los escalones de la entrada. Alguien más echaba la culpa a las hamburguesas, al calor del verano, al dinero, al correo, a las asistentas de color. Para otros la causa radicaba en las granjas de cerdos de los alrededores o los italianos. También los disminuidos psíquicos llevaban su parte, caso de Horace, el deficiente de barrio que estaba siempre lleno de mugre.

Los pudientes decidieron abandonar la zona enfermiza refugiándose en unas casitas cercanas a la playa "para respirar el fresco y tonificante aire del océano". Los menos privilegiados se quedaron allí haciendo lo mismo de siempre. En el caso de los niños la vida rutinaria los llevaba a su colegio bajo la supervisión de Eugene Cantor, "Bucky",

a. Autor de la saga de Sherlock Holmes, 1891-1926. 


\section{NÉMESIS DE PHILIP ROTH FRENTE AL COVID-19 ACTUAL. LA LITERATURA, LAS \\ ENFERMEDADES DEL PASADO Y LA PANDEMIA QUE ESTAMOS PADECIENDO. COVADONGA PIPA MUÑIZ; LUIS VICENTE SÁNCHEZ FERNÁNDEZ}

estudiante universitario y profesor de Educación Física, quien tenía claro que era preciso "que sus vidas sigan siendo lo más normales posibles". Con este pensamiento les arengaba así:

- Muchachos [...], no quiero que empecéis a sentir pánico. La polio es una enfermedad con la que tenemos que vivir todos los veranos. Se trata de una enfermedad grave que siempre ha estado ahí. La mejor forma de enfrentarse a la amenza de la polio es mantenerse sano y fuerte. Procurad lavaros a fondo todos los días, comer bien, dormir ocho horas, tomar ocho vasos de agua diariamente y no ceder a las preocupaciones y los temores.

Pero entre la gente popular comenzó a crecer un nerviosismo exacerbado, tanto que el diálogo entre ellos era:

- iY el Consejo de Sanidad no hace nada! [...]

- Deberían inspeccionar la leche que beben los niños. La polio viene de las vacas sucias y de su leche infectada.

- No, no son las vacas - dijo otra mujer-, son las botellas. No esterilizan como es debido esas botellas de leche.

- ¿Por qué no fumigan? -planteó otra voz?-. ¿Por qué no usan desinfectantes? Que lo desinfecten todo.

- ¿Por qué no hacen lo que se hacía en mi infancia? Nos ataban bolas de alcanfor alrededor del cuello. Había una cosa que olía mal llamada asafétida. A lo mejor eso sería útil ahora.

- ¿'Por qué no extienden alguna sustancia química por las caller y matan al gérmen de esa manera?

- Olvídense de las sustancias químicas -dijo otra vecina- lo más importante es que los niños se laven las manos continuamente. iLimpieza! ¡Limpieza es la única cura!.

Más adelante se llegó a pedir el establecimiento de una cuarentena sobre las casas afectadas, o incluso se les exigía, al menos, a los pacientes llevar un brazalete identitificativo. Igualmente comentaban que la ciencia apenas tenía respuestas ciertas.

Finalizamos este análisis resaltando dos apuntes. Por un lado ofrecemos la entereza de un padre que acababa de perder a su hijo de doce años. Su dolor queda sobradamente reflejado rememorando que tenía al

... mejor muchacho que podías desear, y ha desaparecido [...]. En cuanto vino el médico llamó de inmediato a la ambulancia, en el hospital se lo llevaron de nuestro lado... y eso fue todo. No volvimos a ver a nuestro hijo. Murió solo. No tuvimos ocasión de despedirnos. Todo lo que nos queda de él son su ropa, sus libros de texto, su material deportivo, y ahí al fondo sus peces.

O cuando el sanitario más importante del lugar, el Dr. Steinberg, reconocía que él también temblaba ante esta epidemia; así mismo aceptaba que "ser médico e incapaz de detener la propagación de esta terrible enfermedad es doloroso para todos nosotros". En la misma línea aconsejaba no encerrar a los niños en sus casas, ni menos huir; porque el miedo "castra. El miedo nos degrada".

Con estos pasajes razonamos que la Historia de la Medicina nos enseña que lo ocurrido en este relato es idéntico a otras epidemias del pasado (peste en la Edad Media, cólera en el siglo XIX, gripe de 1918, etc.). Esto es así, porque ante cualquier dificultad extrema en el ser humano relucen unos instintos primarios, aletargados por la educación y el disfrute de unas buenas condiciones de vida, que lo transforman en un ser violento y sin piedad. Veamos cual es la respuesta en esta obra concreta: 1 . Miedo colectivo ante la tragedia que oteaba sobre el horizonte y que quebró por entero el "sueño americano", generando una gente obsesiva y temerosa frente a la posibilidad de contagio y que decidió simplemente huir de su territorio infectado 


\section{NÉMESIS DE PHILIP ROTH FRENTE AL COVID-19 ACTUAL. LA LITERATURA, LAS \\ ENFERMEDADES DEL PASADO Y LA PANDEMIA QUE ESTAMOS PADECIENDO. COVADONGA PIPA MUÑIZ; LUIS VICENTE SÁNCHEZ FERNÁNDEZ}

demostrando insolidaridad ante los más débiles. Una fuga desesperada frente a los marginales y pobres exacerbada por un egoismo a ultranzab. 2. La idea de levantar unas barricadas e implantar una cuarentena ${ }^{c}$ con fumigación a los sospecho$\operatorname{sos}^{d}$ y 3 . La búsqueda de un "chivo expiatorio" (gatos callejeros, perros vagabundos, asistentas de color, los italianos, etc.).

En el momento actual, al igual que en Némesis, esta patología novedosa y mortal que nos acecha desestabiliza nuestro "sistema de bienestar" y hace sacar al exterior lo peor de nosotros. Todo empieza por el miedo a enfermar, situación por otra parte normal; pero, a continuación aflora la miseria humana con el rechazo al otro, al prójimo -al "próximo" o más cercano-. De ahí, el temor al contagio de los que nos llegan de afuera, pongamos por ejemplo de Madrid o de cómo los norteamericanos nada más que fueron concientes de lo que se les venía encima se acercaron a las armerías para tener un fusil o un revólver más a su alcance. También destacamos a los delatores que denuncian o se enfrentan a los que no llevan mascarilla, a los que no guardan la distancia de seguridad, etc. y que nos hace caer en ese derrotismo colectivo que va dañando paulatínamente el respeto y la convivencia por el apego egoista, sin escrúpulos y carente de educación en valores que se antepone a sí mismo por encima de los demás, -al "yoismo"e- imperante, "el mal oculto del siglo XXI" -en palabras del psicólogo Julio Rodríguez- ${ }^{f}$. Por esta simple razón culpamos a China, a Italia, al gobierno de la nación, a los médicos que regresan a casa después de una jornada agotadora y se encuentran con una pancarta, y no precisamente de bienvenida, en el portal de su propia vivienda hecha por sus vecinos. Esa misma gente que hasta ese intante se sentía afortunada de tener un profesional sanitario a escasos metros de su hogar.

Igualmente, se comenta que esta pandemia es debido a la gente materialista, consumidora

b. En su momento, ante entidades epidémicas contagiosas, Galeno de Pérgamo (129-c. 201/216) recomendaba "Cito, longe fugeas, tarde redeas" y traducido como "Huye rápido, vete lejos y regresa tarde". Medida tomada muy intensamente contra la peste bubónica en la Edad Media y que se mantuvo en vigor hasta las epidemias de cólera del siglo XIX. Aguado Casal M. La epidemia pestilencial general: Discurso médico-político sobre su esencia, definición, conocimiento, causas, signos precursores, remedios, precauciones, \&c., según los dictámenes y observaciones de los mejores autores que la tratan contagiosa. Madrid; 1832: 71.

c. La cuarentena es una herencia del pensamiento hipocrático que consideraba agudas a las enfermedades que aparecían dentro de un periodo de cuarenta días después de aparecer la disfunción orgánica en cuestión. Los pasajes bíblicos refieren el bloqueo de este mismo tiempo sobre los leprosos. Contreras Mas A. Legislación frente a la peste en Mallorca Bajomedieval. Medicina e Historia, 74; 1977: 169 y McNeill W.H. Plagas y Pueblos. Madrid: Siglo XXI; 1984: 169.

d. La fumigación comenzó a hacerse ya en épocas remotas; así existen documentos escritos por Homero en el que se indica el uso del azufre como sustancia "purificadora" para eliminar hongos. El rey de Persia, Jerjes (519 a. C.-465 a.C.), usó flores de piretro como insecticida y los chinos se sirvieron de los arsenitos para el control de roedores y plagas. Del Puerto Rodríguez A. M., Suárez Tamayo S., Palacio Estrada D. Efectos de los plaguicidas sobre el ambiente y la salud. Revista Cubana de Higiene y Epidemiología, 52(3); 2014: 372.

e. "Yoísmo", término no reconocido por la Real Academia Española (RAE). Concepto emparentado con el egocentrismo y el narcisimo. Su practicante es una persona que se cree el centro de gravedad de todo lo que le rodea. A tal fin, véanse las redes sociales con imágenes de seres perfectos y sin defectos que no admiten las críticas negativas. Carecen de empatía porque solo se gustan "a sí mismos". En: https://www.abc.es/bienestar/psicologia-sexo/abci-yoismo-201909291209_noticia.html.

f. Más información en: Rodríguez López J. Prevenir el narcisismo. Educa a tu hijo para ser feliz, no para ser el mejor. Barcelona: Plataforma Actual; 2018.

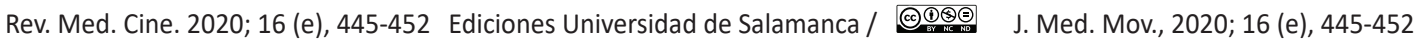
[ 448 ] 


\section{NÉMESIS DE PHILIP ROTH FRENTE AL COVID-19 ACTUAL. LA LITERATURA, LAS \\ ENFERMEDADES DEL PASADO Y LA PANDEMIA QUE ESTAMOS PADECIENDO. COVADONGA PIPA MUÑIZ; LUIS VICENTE SÁNCHEZ FERNÁNDEZ}

desbocada de bienes y servicios y completamente superficial criada bajo el influjo de la globalización que no controla adecuadamente el medio ambiente que nos rodea. Cuestión que lleva a una cercanía cada vez más extrecha con el mundo salvaje y portador de estos virus dañinos. Pero, ¿quién está dispuesto a perder las prebendas de las que gozamos por esta condición? (nos calentamos en el invierno con el gas de Argelia, movemos el coche con restos fósiles del Golfo Pérsico, nuestro teléfono móvil funciona gracias a metales raros -wolframio- de Centroáfrica, etc.).

De momento no se observa excesiva insolidaridad en nuestra patria, aunque los índices económicos no son muy distintos de lo ocurrido con la crisis financiera de 1929 en los EEUU de América, porque el Gobierno de España está protegiendo a los más vulnerables con los Expedientes de Regulación de Empleo Temporal (ERTE) y el salario vital. Con esta cortina de humo la población hedonista española se lanzó a disfrutar de un verano de diversión, a la compra compulsiva en las rebajas o a pelearse -literalmente- por una mesa en una terraza. Un auténtico Carpe Diem (iAprovecha el día!) como si estuviésemos padeciendo la peste bubónica de la Edad media. Veremos que va a pasar cuando se suban impuestos para pagar estos despilfarros. Quizás en ese momento pidamos la llegada de la Némesis vengadora de Philip Roth.

Otro detalle a destacar es la sensación de inmortalidad -ciclo vital: nacer, crecer, reproducirse y morir- que impera en el mundo occidental, auspiciado en parte por el buen nivel de la medicina. El pensamiento adolescente o inmaduro de nuestra sociedad actual rechaza claramente la última etapa porque cree que estamos a punto de ser "dioses". Pero lo que realmente nos llama la atención es como nuestro tiempo adoptó una palabra: "posverdad"; que no es más que un eufemismo para encubrir su sentido real: una auténtica "falacia". Problema alentado desde hace un tiempo y que determina que una ciudadanía sin pensamiento crítico, y sin autoestima, sobreviva rodeada de una "pandemia de mentiras" manipulando a los demás sin ningún pudor para buscar exclusivamente su propio beneficio. Asunto que no es novedoso en absoluto, ya que se encuentra enraizado de manera específica en la clase política. Con unas breves pinceladas analizaremos lo ocurrido al respecto a lo largo de la historia siguiendo la estela de filósofos, religiosos o pensadores en general como: Sócrates (470 a. C.-399 a. C.), Platón (c. 427 a. C.-347 a. C.), Agustín de Hipona, "san Agustín" (354-430), Santo Tomás de Aquino (1225-1274), Martín Lutero (1483-1546), Francisco de Quevedo (1580-1645), Friedrich Wilhelm Nietzsche (1844-1900) y Alexandre Koyré (1892-1964).

Existe una expresión bíblica que dice: "no darás falso testimonio contra tu prójimo"j. Madeja que pretendemos desarrrollar empezando por Sócrates, quien afirmaba que

No debemos preocuparnos de lo que diga la mayoría de la gente, sino sólo lo que diga el experto en cosas justas, único capaz de decirnos la verdad misma ${ }^{3}$.

g. Carpe diem es una locución latina dicha por el poeta romano Horacio (65 a. C.-8 a. C.).

Ante estas, y otras necedades humanas, recomendamos el análisis reflexivo de dos pintores. Veamos El triunfo de la muerte de Pieter Brueghel el viejo (1526-1569) o La piedra de la Locura y El país de la Jauja de el Bosco (c. 1450-1516) para que apreciemos lo efimero de los bienes materiales que con tanto afán pretendemos conseguir. i. De pos y verdad. 1. f. Distorsión deliberada de una realidad, que manipula creencias y emociones con el fin de influir en la opinión publica y en actitudes sociales. Ejemplo: Los demagogos son maestros de la posverdad. En: https://dle.rae.es/posverdad.

j. Éxodo. 20, 16; también destacamos "No jurarás falsamente y cumplirás los juramentos hechos al señor" (Mateo 5-33). 


\section{NÉMESIS DE PHILIP ROTH FRENTE AL COVID-19 ACTUAL. LA LITERATURA, LAS \\ ENFERMEDADES DEL PASADO Y LA PANDEMIA QUE ESTAMOS PADECIENDO. COVADONGA PIPA MUÑIZ; LUIS VICENTE SÁNCHEZ FERNÁNDEZ}

Incomprendido por esa idéntica "mayoría" fue acusado de perturbador de la vida pública y de corromper a la juventud a quienes incitaba -según sus denunciantes- a no seguir las viejas costumbres. Él mismo se defendió planteando cuestiones éticas o de como la injusticia se debe de defender con valores y verdad. Su sentencia inapelable: beber cicuta. Bien es verdad, que tuvo la posibilidad del destierro, pero prefirió cumplir con dignidad el fallo de los jueces ${ }^{4}$. Asimismo nos encontramos con Platón, pensador que afirmaba que

Mientras allí se nos dijo que la verdadera mentira es detestada por todos, dioses y hombres, pues nadie querría voluntariamente estar en el error ${ }^{5}$.

Dando un paso más apreciamos que tanto a Platón como a Aristóteles les preocupaba "la eficacia de la verdad"; puesto que estaban convencidos de que esta comentada desnuda no siempre resultaba eficaz porque era necesario persuadir al auditorio respectivo. Sócrates admitía que los dirigentes de la polis podían disponer, en su calidad de sabios, del derecho al embuste cuando lo considerasen necesario. De ahí el peligro de crear un discurso falso, "la mentira política", para conseguir el apoyo de la mayor parte de la población. Disputa propia de los demagogos ${ }^{6}$.

Continuamos con San Agustín, del cual destacamos que fue quien mejor definió el concepto que tratamos; de esta manera dejó escrito que "mentira es la significación de una cosa falsa unida a la voluntad de engañar"; entendemos por tanto, que no miente quien no dice la verdad, sino "quien dice aquello que no cree que sea verdad $^{\prime \prime}$. No obstante, matizaba que mentir con el fin de dar algún beneficio a otro, no sería excesivamente grave y se consideraría "un pecado venial". Santo Tomás de Aquino inspirándonos en lo dicho por San Agustín clasificó el tema en tres grandes géneros: la mentira "dañina" que tiende a perjudicar al prójimo, la "graciosa" para divertirse y finalmente la "oficiosa" con la que se busca ayudar a los demás. Tripartición que será el fundamento de la doctrina católica sobre la mendacidad $^{7}$. Por otra parte la teología clásica defiende que la verdad mantiene correspondencia o adecuación entre el enunciado y la realidad ${ }^{8}$.

De Martín Lutero, líder de la reforma protestante, tan sólo subrayamos el odio cerval que propugnó sobre el judaísmo vertido en su libro Sobre los judíos y sus mentiras'.

El genial dramaturgo madrileño Francisco de Quevedo escribió el "Valimiento de la mentira"; dice así:

Mal oficio es mentir, pero abrigado: eso tiene de sastre la mentira, que viste al que la dice; y aún si aspira a puesto el mentiroso, es bien premiado.

Pues la verdad amarga, tal bocado mi boca escupa con enojo y ira; y ayuno, el verdadero, que suspira, invidie mi pellejo bien curado.

Yo trocaré mentiras a dineros, que las mentiras ya quebrantan peñas. y pidiendo andaré en los mentideros.

Prestadas las mentiras a las dueñas: que me las den a censo caballeros, que me las vendan Lamias alagüeñas ${ }^{9}$.

k. Igualmente matizaba que había dos tipos de verdad: la ontológica, entendida como correspondencia entre lo que se afirma y lo que es verdad, y la moral, entendida como "veracidad" o "veridicción", entendida como la conformidad entre lo que se dice y lo que se piensa. Gramigna, 2001: $48^{7}$.

I. Escrito en 1543. En él vertía opiniones de que los seguidores de esa religión tenían que ser enviados a trabajos forzados o incluso podían ser asesinados. 


\section{NÉMESIS DE PHILIP ROTH FRENTE AL COVID-19 ACTUAL. LA LITERATURA, LAS \\ ENFERMEDADES DEL PASADO Y LA PANDEMIA QUE ESTAMOS PADECIENDO. COVADONGA PIPA MUÑIZ; LUIS VICENTE SÁNCHEZ FERNÁNDEZ}

Realidad socio-económica de la España de Felipe III y Felipe IV que se simplifica con la unión del dinero y las mentiras; aspectos reforzados con la corriente imperialista del país gracias a los metales nobles que llegaban de América. Sinergia poderosa que atraía a todos los estamentos: gobernantes y gobernados; a pesar de que los teólogos y moralistas condenaban la mentira como pecado grave. La moneda falsa estaba también mal vista y los que mercadeaban con ella podían ser quemados vivos.

Nietzsche afirmaba que la capacidad de sobrevivir del individuo está cuestionada constantemente por el intelecto gracias a que desarrolla sus fuerzas primordiales en la ficción. Arte que

... alcanza su máxima expresión en el hombre: aquí el engaño, la adulación, la mentira y el fraude, la murmuración, la hipocresía, el vivir ajeno, el enmascaramiento, el convencionalismo encubridor, el teatro ante los demás y ante uno mismo, en una palabra, el revoloteo incesante ante la llama de la vanidad es hasta tal punto la regla y la ley, que apenas hay nada más inconcebible que el hecho de que haya podido surgir entre los hombres un impulso sincero y puro hacia la verdad ${ }^{10}$.

Autor que suaviza un tanto este trasunto al plasmar que ese mismo hombre "tanto por necesidad como por aburrimiento, desea existir en sociedad y gregariamente, precisa un tratado de paz", aunque originando un conflicto entre verdad y mentira. Razonamiento por el que deduce que la verdad es sólo "un ejército móvil de metáforas, metonimias, antropomorfismos" que permite o favorece "la obligación de mentir según una convención firme". Dicho de otra manera: la mentira es nuestro medio de subsistencia.

El francés Koyré en La función política de la mentira moderna, 1943, -harto de Goebbels y de la complicidad estúpida de la aristocracia europea- planteaba como los estados del momento, catalogados en su mayoría como "democráticos", mantenían una suficiente desinformación en las masas de temas claves para manejar la opinión pública produciendo un importante cúmulo de mentiras. En 2015, setenta y dos años después, se volvió a publicar dicho ensayo y su prologuista, Sánchez Pintado, dejó anotado que "es innegable que el hombre ha mentido siempre". Lo llamativo es que

Nunca se ha mentido tanto como en nuestros días, ni de manera tan desvergonzada, sistemática y constante ${ }^{11}$.

En la época de Sócrates y Platón a estos manipuladores se les denominaba "demagogos", en nuestra época quedan rebajados a meros "propagandistas" y ante la falta de masa crucial puede ocurrir lo dicho en su momento por el filósofo griego Gorgias (c. 485 a. C.-c. 380 a. C.), quien ante la imposibilidad de convencer a los tesalios, comentó: "son demasiado ignorantes para ser engañados por mí"12 o de como Marco Aurelio (121-180), escribió seiscientos años más tarde que el memorable Sócrates que "la mentira es una peste tan peligrosa como la contaminación del aíre que respiramos"13.

\section{CONCLUSIÓN}

Cualquier epidemia del pasado acarreó a los coetáneos un sufrimiento personal significativo como consecuencia de la alta mortalidad y del deterioro económico consecuente; piénsese en el efecto que pudo traer la peste bubónica que provocó la defunción de un tercio de la población europea.

El brote de poliomielitis que nos describe Pilipp Roth nos sirve de ejemplo para que analicemos la eclosión de instintos básicos negativos entre la población. La COVID-19 camina por la misma senda; veremos en un futuro próximo las consecuencias socio-económicas.

Para finalizar tan solo anotamos una cifra: 270.000 españoles muertos durante la 


\section{NÉMESIS DE PHILIP ROTH FRENTE AL COVID-19 ACTUAL. LA LITERATURA, LAS \\ ENFERMEDADES DEL PASADO Y LA PANDEMIA QUE ESTAMOS PADECIENDO. COVADONGA PIPA MUÑIZ; LUIS VICENTE SÁNCHEZ FERNÁNDEZ}

epidemida de gripe de 1918/1919. La COVID-19 es una enfermedad seria, pero aún se mantiene en unas cifras moderadas de mortalidad. Debemos desprendernos del "ius ad omnia" (un derecho a todo) que cargamos al Estado para responsabilizarnos, como adultos bien formados, individualmente. De nosotros - de cada unodepende que podamos frenar este brote o que se desboque definitivamente.

\section{REFERENCIAS}

1. Ramírez Camacho R. Escritores médicos, médicos escritores y médicos que escriben. Seminario médico. 2017; 62 (1): 65-84.

2. Roth Ph. Némesis. Barcelona: Mondadori; 2011.

3. Díaz M.E., Kulesz O., Spangenber P., Meli F. y Marcos de Pinoti M.E. ¿Sólo persuade el engaño? Filosofos y sofistas en torno a la eficacia de la verdad. V Jornadas de Investigación en Filosofía. Universidad Nacional de la Plata. Facultad de Humanidades y Ciencias de la Educación. Departamento de Filosofía, La Plata. 2004.

4. Cuardini R. La muerte de Sócrates. Una interpretación de los escritos platónicos Eutifón, Apología, Critón y Fedón. Madrid: Ediciones Palabra; 2016.

5. Marcos de Pinotti G.E. Mentiras semejantes a verdades según Platón. Justificación y alcance del "pseudos" en "República II". Revista Filosófica Univ. Costa Rica. 2008, XLVI (117/118): 95-103.
6. Díaz M.E., Kulesz O., Spangenber P., Meli F. y Marcos de Pinoti M.E. ¿Sólo persuade el engaño? Filosofos y sofistas en torno a la eficacia de la verdad. V Jornadas de Investigación en Filosofía. Universidad Nacional de la Plata. Facultad de Humanidades y Ciencias de la Educación. Departamento de Filosofía, La Plata. 2004.

7. Gramigna R. La mentira en San Agustín. Universidad de Rosario (Argentina). Versión electrónica:designisfeis.net. 2001: 45-55.

8. Vide Rodríguez V. Análisis filosófico y teológico de la mentira desde la teoría de los actos del habla. Perseitas. 2016; 4(2): 153-75.

9. Sokol A. Dinero y valor en el soneto Valimiento de la mentira de Quevedo. 2002. AISO, actas.VI.

10. Nietzsche F. Sobre verdad y mentira en sentido extramoral. En: repositorio.uam.es]]xmlui]]bitstream]] handle]]2202.

11. Sánchez Pintado F. Prólogo. En: Koyré A. La función política de la mentira moderna. Madrid: Pasos Perdidos. 2015.

12. Spangerberg P. Persuasión y verdad de Georgias y Platón. V Jornadas de Investigación en Filosofía. Universidad Nacional de la Plata. Facultad de Humanidades y Ciencias de la Educación. Departamento de Filosofía, La Plata. 2004.

13. Coscollar Santaliestra A. Sócrates y las mentiras. Tribuna Digital. 2 de agosto de 2010.

\begin{tabular}{|l|l|l|l|l} 
Luis Vicente Sánchez Fernández es Profesor asociado de Historia de la Cien- \\
cia (H.a de la Medicina) en la Facultad de Medicina de la Universidad de \\
Oviedo. Médico del SESPA en el Servicio de Atención Continuada en el \\
Centro de Salud de Lugones. Autor de cuatro libros y de varios artículos \\
científicos de temas relacionados con la Historia de la medicina asturiana.
\end{tabular}

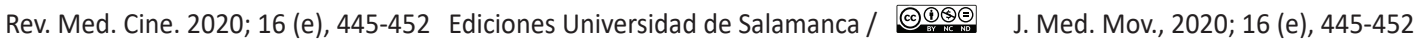
[ 452 ] 